\title{
Research on the Strategies How Enterprises Deal with the Internet Rumors in the New Media Era
}

\author{
Gao Jincheng \\ Wuhan Business University, Wuhan, 430056, China \\ E-mail: gao.sun001@126.com
}

Keywords: New Media Age; Internet Rumors; Enterprise Crisis; Strategy

\begin{abstract}
As the new media era arrival, new media such as blog, Weibo, WeChat and QQ provide convenient and fast access to information for the people, and also has become a hotbed for the breeding and rapid spread of rumors in cyberspace. Based on the analysis of the characteristics of Internet rumors in the new media era, this paper focuses on the sources and harms of Internet rumors about enterprises, and proposes targeted strategies for enterprises to cope with the crisis caused by Internet rumors.
\end{abstract}

\section{Introduction}

With the advent of the new media era, new media such as blog, Weibo, WeChat and QQ provide convenient and fast access to information for the audience, and also has become a hotbed for the breeding and rapid spread of rumors in cyberspace. Due to the interactivity, openness and convenience of the new media, Internet rumors that are sometimes difficult to distinguish between truth and false will be arbitrarily amplified in the cyberspace. The generation of Internet rumors and their spread will not only seriously affect normal production and operation activities, but also bring a detrimental impact on the brand image of enterprises. Therefore, how to deal with the corporate crisis brought about by Internet rumors in the new media era is of paramount significance for enterprises.

\section{Features of Internet Rumors in the New Media Era}

Internet rumors are unsubstantiated messages or speeches spread through various Internet websites, chat software, social platforms, BBS and other Internet media. New media era has witnessed the expended discourse space of the public. Due to the interactivity, openness and convenience of new media, Internet rumors that are sometimes difficult to distinguish between truth and false will be arbitrarily amplified and spread rapidly in the cyberspace. Specifically, Internet rumors in the new media era have the following characteristics:

\subsection{Fast spread of Internet rumors}

In the new media era, once Internet rumors are generated, they will spread virally on the network through various new media communication channels such as blog, Weibo, WeChat and QQ. Internet rumors are transmitted to tens of thousands and millions of audiences in a short time through rapid replication. In a sense, the rapid spread of Internet rumors greatly shortens the time for enterprises to cope with the crisis brought by Internet rumors, and thus increases the difficulty for enterprises to cope with them.

\subsection{Wide spread of Internet rumors}

In the process of spreading Internet rumors through various new media channels, the dissemination of information is not limited by time and space, and the spread of Internet rumors covers a wide range. As of June 2018, the number of Chinese netizens has reached 802 million with the penetration rate of $57.7 \%$, among which the number of mobile phone netizens is 788 million with the proportion as high as $98.3 \%$. In a sense, a large number of netizens may become the 
audience of Internet rumors, which continue to affect the other netizens. At the same time, with the widespread spread of Internet rumors, some regional corporate crisis brought by Internet rumors even evolve into national or even international corporate crisis.

\subsection{Internet virtuality makes Internet rumors an outlet for people to express their dissatisfaction}

There is a famous saying by Bill Gates, “On the Internet, nobody knows you are a dog.” In the new media era, although the government has strengthened the real-name system management of the Internet in recent years, the virtuality of the Internet makes Internet rumors become an outlet for people to express their discontent. On the one hand, the Internet awakens the public's awareness of expression and greatly mobilizes the public's enthusiasm to participate in Internet discussions. The public can directly and freely express various opinions and emotions through the Internet. On the other hand, for enterprises in the crisis of Internet rumors, the public can also question, condemn or even attack them through the Internet. These discontented emotions can quickly infect other netizens through various new media, so that the negative impact of Internet rumors on the crisis can be quickly amplified and spread.

\section{The Source of Internet Rumors in the New Media Era}

In the new media era, the Internet rumors that enterprises may face mainly come from the following four aspects:

\subsection{Competitors}

In today's increasingly competitive market, conflict-of-interest competitors will rack their brains to squeeze each other out and gain a larger market share. When the enterprise crisis is caused by various potential risks, competitors will spread some information or remarks without factual basis through the network, thus adding fuel to the fire in the network transmission of the enterprise crisis, which will aggravate the enterprise crisis and also bring greater risks to the enterprise.

\subsection{Consumers}

When enterprises are in crisis due to Internet rumors, some consumers will vent all kinds of dissatisfaction to enterprises accumulated at ordinary times. At this time, they also objectively act as the makers or disseminators of Internet rumors. Some consumers do have dissatisfaction with the enterprise, while some do it completely unconscious in the process of copy, paste and transmission.

\subsection{Internet we-media}

In the new media era, Internet we-media sometimes become the makers or disseminators of Internet rumors due to their neglect of investigation or the violation of professional ethics by individual journalists. Since these Internet we-media generally have a legal cover, they will cause more harm to enterprises if they spread Internet rumors.

\subsection{The public}

In the new media era, people sometimes act intentionally or unintentionally as Internet rumor makers or disseminators. Generally speaking, some people with ulterior motives try to use rumors to confuse the public so as to express their dissatisfaction to the enterprise. The people without ulterior motives has also played a role in promoting the enterprises crisis objectively.

\section{The Harm of Internet Rumors to Enterprises in the New Media Era}

In the new media era, Internet rumors may bring harm to enterprises in the following aspects:

\subsection{Internet rumors affect the public's correct cognition of enterprises}

In the new media era, Internet rumors are generally offensive and purposeful words without factual basis. In the spreading through various new media, such as blogs, Weibo, WeChat, QQ, etc., 
rumors are featured with suddenness and anonymity, and their fast transmission is free from time and space restrictions. Due to its strong demagoguery, it is difficult for the public to distinguish truth and falsehood in a short period of time. Therefore, Internet rumors will not only affect the public's correct cognition of enterprises, but also make enterprises face huge pressure of public opinion. At the same time, under the influence of Internet rumors, employees inside the enterprise will have doubts and low morale. For example, Internet rumors such as "Master Kong illegal cooking oil" and "KFC chicken with six wings" that took place in China in 2015, and the saying "pictures tell the truth" makes it difficult for consumers to distinguish the true from the false, which also brought a great negative impact on the brand reputation of Master Kong and KFC.

\subsection{Internet rumors affect the normal production and operation activities of enterprises}

In the new media era, the Internet rumors related to enterprises may involve all aspects of the production and operation of enterprises, from product production to after-sale service, quality management to technical innovation, financial management to personnel changes, and market competition to enterprise integrity. No matter what aspect of enterprise production and operation is involved in Internet rumors, they can be hard to prevent. Once they appear and spread on the Internet, they will affect normal production and operation activities of enterprises. Once in our country in 2015, for example, the "Wahaha botulinum toxin"Internet rumors brought huge negative effects to the market sales after being spread through new media, and its market sales also suffered a serious decline. In the first quarter of 2015 alone, some products suffered a loss of 2 billion yuan.

\subsection{Internet rumors affect the brand image and corporate image of the enterprise}

In the new media era, Internet rumors will not only affect the normal production and operation activities of enterprises and bring direct economic losses, but also directly affect the brand image and good reputation of enterprises, thus bringing huge indirect economic losses to enterprises. For example, the "plastic seaweed" Internet rumors in 2017 had a significant negative impact on the corporate image of the seaweed producing enterprises in Jinjiang, Fujian province. It can be said that a rumor almost destroyed not only an enterprise but also an industry. In 2018, China's leading dairy company Yili Group, faced a barrage of complaints after "Guangxiang Finance" issued a rumor article namedPan gang, chairman of Yili group, lost contact. According to the Baidu index, the popularity of the search for Yili rose by 300 percent on the day the rumor spread, and finally Yililost 13.19 billion because of this the rumor.

\section{Strategies for Enterprises to Internet Rumors in the New Media Era}

In the new media era, with the emergence and spread of Internet rumors, they will bring serious crisis to enterprises. Generally speaking, enterprises can adopt the following strategies when dealing with Internet rumors:

\subsection{Daily monitoring of Internet public opinions and advance prevention of Internet rumors}

In the new media era, enterprises should do a good job of daily monitoring of Internet public opinions, and monitor the public opinions of various Internet media at any time by setting up special organizations and arranging full-time personnel. At the same time, enterprises need establish the beforehand prevention mechanism of Internet rumors internally, and carefully analyze and confirm the media public opinion related to the enterprise which may bring various negative effects to the enterprise. Meanwhile, it is necessary to analyze the information network transmission channel, so as to avoid and prevent the spread of bad information, and nip rumors in the bud.

\subsection{Proper and timely clarification of Internet rumors}

In the new media era, enterprises should keep calm in the face of sudden and huge Internetrumors, properly and timely clarify the rumors. 


\subsubsection{To investigate the source and specific content of Internet rumors}

No matter what the source of Internet rumors, or whether the producer or disseminator of Internet rumors is intentional or unintentional, the generation and spread of Internet rumors will certainly cause the crisis of enterprises. Therefore, for enterprises, the source and specific content of Internet rumors should be investigated before deciding the next response plan.

\subsubsection{To choose the right way to set the record straight}

After knowing the source and specific content of Internet rumors, enterprises can choose appropriate ways to clarify the truth according to the actual situation. If the rumors maker or disseminator is intentional, the enterprise can clarify the truth through normal channels, such as government departments and trade associations, and at the same time can also require them to immediately stop willful wrong doing. When it is necessary, enterprises can even take legal weapon suing the rumor mongers to defend their own legal interests; If the producer or disseminator of Internet rumors is unintentional, the enterprise can clarify the truth through appropriate channels while seeking cooperation from the other party after explaining the bad influence of rumor mongering, and eliminate all kinds of adverse effects of Internet rumors on the enterprise.

\subsubsection{To take appropriate action when clarifying the facts}

When clarifying the truth, enterprises can choose different strategies according to the actual situation. For rumors producer or disseminator with malicious motives, the enterprise can find relevant data or proof after knowing the object, then directly point out and expose his ugly face, and even call the police and resort to the law when necessary. Rumors is fake after all which cannot be tested. Therefore, when clarifying the truth, the public should be aware of the falsity of rumors. Enterprises can make the rumors public, and finally achieve the goal of breaking the rumors without attack. In the circulation of rumors, the media plays the role of satisfying the public's right to know, while enterprises can also resort to the testimony of authoritative media to crack down Internet rumors as soon as possible and set things right timely.

\subsection{Proper remedial work for Internet rumors}

After clarifying the truth, enterprises ostensibly eliminate the negative impact of Internetrumors, but in fact many of the public is still dubious about Internet rumors. Therefore, the enterprise still needs to do a good job in the remedial work forInternet rumors. By inviting the public to visit the enterprise or participate in the brand experience in person, the public's faith in the enterprise or brand will be strengthened, so as to achieve perfect crisis management.

\section{References}

[1] Chen Jing. Study on the Causes and Countermeasures of Internet Rumors in the Context of New Media [J]. Journal of Hubei Institute of Technology.2016 (11) 139-141.

[2] Gao Jincheng. Marketing Risk Aversion Strategy for Small and Medium-sized Enterprises [M]. Hubei People’s Publishing House.2014-12.

[3] Ma Qiang. Characteristics, Influence and Countermeasures of Internet Rumors in New Media Environment [J]. News Front.2018(6) 52-53.

[4] Rodney. A Brief Analysis of the Impact of New Media on the Spread of Internet Rumors and Its Countermeasures [J]. Journal of Press Research.2017(9) 25-26. 